\title{
Peer Evaluation of Teaching or 'Fear' Evaluation: In Search of Compatibility
}

\author{
Abdel Rahman Abdalla Salih ${ }^{1}$ \\ ${ }^{1}$ Department of English Language \& Literature, Al-Zahra College for Women, Sultanate of Oman \\ Correspondence: Abdel Rahman Abdalla Salih, Department of English Language \& Literature, Al-Zahra College \\ for Women, P. O. Box 3365-P. C., 111-Airport Heights-Muscat, Sultanate of Oman. Tel: 968-9236-8309. E-mail: \\ mujabs@yahoo.com
}

Received: December 6, $2012 \quad$ Accepted: January 23, $2013 \quad$ Online Published: March 25, 2013
$\begin{aligned} & \text { doi:10.5539/hes.v3n2p102 } \\ & \text { URL: http://dx.doi.org/10.5539/hes.v3n2p102 }\end{aligned}$

\begin{abstract}
Peer evaluation or review of teaching is one of the factors of quality assurance system at the present time. However, peer evaluation is sometimes approached with trepidation and with the feeling that it may not be fair and free of bias. This paper examines teachers' perceptions of peer evaluation as an enhancement for quality teaching. A questionnaire was designed and distributed among forty tutors in two higher learning institutes in the Sultanate of Oman. The study drew some results pertaining to the teachers' views of peer evaluation and its impact on teaching quality enhancement.
\end{abstract}

Keywords: peer evaluation/peer review, quality assurance system, quality teaching, subjectivity, professional development

\section{Introduction}

The history of teaching has revealed a pertinent fact that a new relevant practice or an innovation always has a major effect upon teaching, whether methodological or technological. The teaching profession in general and at the tertiary level, in particular, has witnessed a series of 'revolutions' in various aspects by promoting and implementing new practices, techniques and theories. The pre-twentieth-century language teaching practices, for instance, were different from the teaching trends practiced in the twentieth century (Celce-Murcia, 2001). It is worth noting that such changes and shifts happen at varying degrees and speed depending on the field, subject or discipline. Moreover, it has been natural to see each practice receiving different responses and producing different results. The teaching practices prevalent in the twentieth century have been associated with numerous concepts and practices such as effective teacher and effective teaching, exploring teacher beliefs, teacher education, teacher training, teacher perceptions; and all have been introduced to assist teachers perform better and effectively (Borich, 2004). The keen interest into tailoring and exploring the best practices and innovations that may lead to better outcomes is realised by Biggs and Tang (2007) who stated that "the new agenda for universities, to sell education and to provide for market needs, makes them like any other corporation that sells a product" (p. 3).

In recent years, both feedback on teaching for professional development and the teaching practice have witnessed a new phase of revolution by the implementation of the concept of quality assurance (QA) in education which has become an international trend and brand widely adopted by institutions of higher education; and the Sultanate of Oman is no exception. Richards and Schmidt (2002) defined quality assurance as the "system an organization has in place to ensure the quality of its practices" (p. 436). This notion has put significant impact on the teaching practice and is deemed to change its landscape and direction forever. The quality assurance system operates with the view that quality teaching and quality learning are the best response to the market and employment demands for skilful graduates equipped with academic and non-academic skills. In this context, Cowan (2006) viewed teaching as "the purposeful creation of situations from which motivated learners should not be able to escape without learning or developing” (p. 100). Thus, the equation rests on a well-connected cycle of good teaching leading to quality learning outcomes and full satisfaction of the work market. In addition, the effective teaching-learning process enables teachers to receive constructive perspectives on their teaching consistent with motivating students and professional development. As far as feedback for quality teaching is concerned, teacher peer review (PR) or evaluation is one of the fundamental steps in the 
quality assurance system and an important requirement for teacher growth and development. Biggs and Tang (2007) defined peer review as a process for the evaluation of teaching by a colleague; and identified the rationale behind peer review system as they argued that "the primary purpose of peer review is to provide formative feedback for continuing professional development of individual teachers" (p. 269). Taking quality assurance and professional development as two basic purposes of teacher evaluation process, Danielson and McGreal (2000) suggested that peer evaluation of teaching is designed to provide either formative feedback for enhancing teacher development and good practices, or summative feedback for personnel decision making such as promotion/tenure renewal, or reappointment. Peer evaluation or review is, then, a process where teachers are evaluated by peers on a number of identifiable aspects (academic, interpersonal, and intrapersonal) covering specific areas such as teaching methods, assessment preparation, materials development, scholastic activities, to provide feedback for reflection on teaching and professional growth. Quality-oriented teaching is believed to be grounded on continuous reflection on practice by teachers in order to develop professionally and motivate students' active engagement in the learning process (Cowan, 2006). It could be argued that lecturers' awareness of teaching-learning process within the notion of quality assurance in teaching is an important factor for effective peer evaluation of teaching and the lecturers' willingness to take part in the process. However, the quality assurance system and its call for feedback on teaching for quality learning raises some concerns and controversy as it is seen by some as unnecessary and as such it should be approached cautiously. In this context, peer evaluation in particular was not taken positively by many teachers who feel that it opens the door for bias and subjectivity as well as interference in their teaching (Saarinen, 2010; Danielson \& MacGreal, 2000). As far the present study's setting is concerned, it is important to note that different institutions of higher learning in the Sultanate of Oman have different procedures and purposes in practicing peer evaluation exercise. The current practice in peer evaluation bears on summative purposes by some institutions of higher education and on formative purposes or the combination of both by some other institutions. An absence of a unified system for the execution of peer evaluation across universities and colleges is expected to raise fear and rejection among tutors and create some unwanted problems. Thus, uniformity of procedures and purposes in conducting peer evaluation in these institutions is imperative without which the whole supreme purpose of the quality assurance practices in teaching may be jeopardised.

The changing scene of learning and teaching in higher education in recent years presents teachers with challenges one of which is to develop transformative reflection and look positively on the perspective provided by colleagues or peers who are "in the role of critical friend" (Biggs \& Tang, 2007, p. 46). Research has attempted to explore the significance of peer evaluation for teaching and teacher professional development. Sullivan, Buckle, Nicky, and Atkinson (2012) examined the three steps of peer evaluation: pre-observation meeting, observation, and post observation feedback and concluded that teachers found both written and verbal feedback constructive and useful for reflection and enhancement of teaching. In their study, Kumrow and Dahlen (2002) examined a number of aspects of peer review such as process, objective, usefulness as well as financial implications and concluded that peer review practice has effects for evaluating teachers and promoting good teaching practices. In another study, Bodenhausen (1990) explored teachers' attitudes toward peer evaluation and the factors that shaped them. The researcher concluded that teachers' support or opposition to peer evaluation is affected by some factors such as the structure of evaluation, professionalism, and role of administration which need to be taken into consideration in assessing teachers' reaction towards peer review. Lomas and Nicholls (2005) examined the introduction of peer review of teaching in higher education in England and the effect of the practice in enhancing teaching quality. The researchers argued that an understanding of the concept of peer review of teaching in itself is crucial in perceiving it as a mere process for quality enhancement or a significant tool in quality assurance. Saarinen (2010) assessed the evolution of the concept of quality assurance in higher education in the last fifteen years and its development from an issue of controversy and rejection to a well-consolidated and acceptable practice. The author demonstrated how quality assurance has provided a paradigmatic shift in higher education by moving the focus from the debate on the relevance and validity of the system to practical issues relating to the best way of implementing it. This study is significant as it asserted the relevance of practices such as peer evaluation of teaching in the quality assurance system. It is a pertinent fact that a clear understanding of peer review as a quality assurance process for the empowerment of teaching and teacher professional development encourages the adoption of the process rather than to be viewed as an imposed policy for quality enhancement.

It could be argued that despite the growing interest in peer evaluation as a quality assurance instrument and its beneficial effects on teaching and learning development, more research is needed about teachers' perceptions towards the process of peer evaluation and its possible impact on the whole teaching practice. Thus, research that 
investigates teachers' reactions towards peer assessment is imperative. Such research will need to highlight peer evaluation process, reviewer's focus, reviewee's preferences and the effects of feedback on teaching and in guiding teachers' professional growth and development. Thus, there is a necessity to advocate the examination of teachers' responses to peers evaluation and the effect of that on the quality of teaching and learning. This paper reports the views of English language teachers in two higher education institutes in the Sultanate of Oman about peer evaluation and feedback on teaching. Specifically, the study addressed the following questions:

1. How do teachers view peer review?

2. To what extent do views of peers affect a teacher's performance?

3. How does peer review enhance teaching quality?

4. Why is peer evaluation disfavoured by some teachers?

\section{Method}

This study explores English language teachers' reactions towards peer feedback. To achieve such an objective, a questionnaire, focusing on different aspects of peer evaluation, (see Appendix) was designed by the researcher and distributed to total of (40) teachers with varieties of experiences in teaching English in (2) higher learning institutes in the Sultanate of Oman. The two colleges in the study run both General Foundation Programme (GFP) and BA degree in English and adopt peer evaluation as one of the essential requirements in the quality assurance systems and procedures. All the participants $(\mathrm{N}=40)$ had taken part in peer evaluation before, and were given the right to choose their review partners. Peer evaluation process followed the three steps of pre-observation meeting to discuss the visit timing or any other issue of concern, observation where the teacher would be evaluated in terms of teaching and materials, and post-observation or follow-up meeting/discussion in order to highlight points and aspects of good practices and areas of improvement and development.

\subsection{Procedures}

This study utilised one source of data: questionnaire surveys. Researchers commonly employ questionnaires as instrumentation to elicit data. To meet their objectives, researchers, may design questionnaires to explore subjects' attitudes and personal characteristics (Larsen-Freeman \& Long, 1991; Karava-Doukas, 1996). The questionnaire (Appendix) was designed to explore the respondents' perceptions about providing to and receiving feedback from peers. The questionnaire was also administered to understand the effects of peer review on teacher reflection, the teaching process, and teacher professional growth and development. The statements in the questionnaire were placed in random order, and next to the statements were five columns with five options: 'strongly agree', 'agree', 'uncertain', 'disagree', and 'strongly disagree'. The values 5, 4, 3, 2, and 1 were placed under the five options respectively, i.e., 'strongly agree' $=5$, 'agree' $=4$, 'uncertain' $=3$, 'disagree' $=2$, 'strongly disagree' $=1$. Informants were told to select their favourable items by placing a tick in the box. By so doing, it was possible to ascertain the respondents' agreement or disagreement with the statements and explore their perceptions about the issue the item discussed.

\section{Results and Discussion}

The questionnaire sheets (40 sheets in 23 items) were collected and analysed to examine the respondents' views on the significance of peer review practice for reflection and professional development. The informants' responses to each item were calculated and frequencies and percentage equivalents were taken as shown in Table1 below. 
Table 1. Peer evaluation questionnaire frequency count and percentage equivalent

\begin{tabular}{|c|c|c|c|c|c|}
\hline & S.A & A & $\mathrm{U}$ & $\mathrm{D}$ & S.D \\
\hline \multicolumn{6}{|l|}{ Questionnaire items: } \\
\hline Peer evaluation is useful in teaching. & $12(30 \%)$ & $23(57.5 \%)$ & $5(12.5 \%)$ & - & - \\
\hline I prefer to choose my reviewer(s) and reviewee(s). & $2(5 \%)$ & $9(22.5 \%)$ & $12(30 \%)$ & $5(12.5 \%)$ & $12(30 \%)$ \\
\hline I always look positively about peer evaluation. & $16(40 \%)$ & $16(40 \%)$ & $6(15 \%)$ & $1(2.5 \%)$ & $1(2.5 \%)$ \\
\hline $\begin{array}{l}\text { In the peer evaluation sessions, I found it interesting } \\
\text { to exchange feedback with colleagues. }\end{array}$ & $14(35 \%)$ & $22(55 \%)$ & $3(7.5 \%)$ & - & $1(2.5 \%)$ \\
\hline I can only carry out peer evaluation with friends. & - & $3(7.5 \%)$ & $8(20 \%)$ & $15(37.5 \%)$ & $14(35 \%)$ \\
\hline Peer evaluation may be bias sometimes. & $7(17.5 \%)$ & $19(47.5 \%)$ & $11(27.5 \%)$ & $1(2.5 \%)$ & $2(5 \%)$ \\
\hline $\begin{array}{l}\text { Peer evaluation doesn't work objectively when there } \\
\text { is some misunderstanding among staff. }\end{array}$ & $13(32.5 \%)$ & $20(50 \%)$ & $6(15 \%)$ & - & $1(2.5 \%)$ \\
\hline $\begin{array}{l}\text { Peer evaluation helps me to develop positive relations } \\
\text { with my colleagues. }\end{array}$ & $5(12.5 \%)$ & $17(42.5 \%)$ & $15(37.5 \%)$ & $2(5 \%)$ & $1(2.5 \%)$ \\
\hline $\begin{array}{l}\text { Peer evaluation enables me to reflect on my teaching } \\
\text { positively. }\end{array}$ & $18(45 \%)$ & $20(50 \%)$ & $2(5 \%)$ & - & - \\
\hline I find all reviewers' feedback useful. & $8(20 \%)$ & $22(55 \%)$ & $7(17.5 \%)$ & - & $3(7.5 \%)$ \\
\hline $\begin{array}{l}\text { Peer evaluation exercise enables me to give } \\
\text { suggestions to my colleagues. }\end{array}$ & $8(20 \%)$ & $28(70 \%)$ & $4(10 \%)$ & - & - \\
\hline The feedback given is always constructive. & $1(2.5 \%)$ & $17(42.5 \%)$ & $18(45 \%)$ & $1(2.5 \%)$ & $3(7.5 \%)$ \\
\hline $\begin{array}{l}\text { Through peer evaluation I feel I develop } \\
\text { professionalism in teaching. }\end{array}$ & $8(20 \%)$ & $21(52.5 \%)$ & $8(20 \%)$ & $1(2.5 \%)$ & $2(5 \%)$ \\
\hline $\begin{array}{l}\text { Peer evaluation motivates my research interest and } \\
\text { activities. }\end{array}$ & $6(15 \%)$ & $21(52.5 \%)$ & $9(22.5 \%)$ & $2(5 \%)$ & $2(5 \%)$ \\
\hline $\begin{array}{l}\text { The feedback I get from my reviewers helps me } \\
\text { to modify my teaching methods. }\end{array}$ & $12(30 \%)$ & $26(65 \%)$ & $2(5 \%)$ & - & - \\
\hline $\begin{array}{l}\text { In peer evaluation I focus mainly on rating my } \\
\text { colleagues' weaknesses. }\end{array}$ & $2(5 \%)$ & $1(2.5 \%)$ & $5(12.5 \%)$ & $20(50 \%)$ & $12(30 \%)$ \\
\hline $\begin{array}{l}\text { I prefer to receive additional oral feedback from my } \\
\text { reviewer(s) during review sessions as well. }\end{array}$ & $9(22.5 \%)$ & $21(52.5 \%)$ & $4(10 \%)$ & $2(5 \%)$ & $4(10 \%)$ \\
\hline $\begin{array}{l}\text { Peer evaluation draws my attention to certain } \\
\text { areas that I overlook to improve. }\end{array}$ & $12(30 \%)$ & $23(57.5 \%)$ & $3(7.5 \%)$ & - & $2(5 \%)$ \\
\hline $\begin{array}{l}\text { Since I have rich experience in teaching, } \\
\text { peer evaluation is not necessary. }\end{array}$ & - & $1(2.5 \%)$ & $5(12.5 \%)$ & $14(35 \%)$ & $20(50 \%)$ \\
\hline $\begin{array}{l}\text { My junior colleagues are unable } \\
\text { to evaluate me effectively. }\end{array}$ & - & $2(5 \%)$ & $16(40 \%)$ & $10(25 \%)$ & $12(30 \%)$ \\
\hline $\begin{array}{l}\text { Peer evaluation gives me more } \\
\text { confidence about myself. }\end{array}$ & $8(20 \%)$ & $26(65 \%)$ & $5(12.5 \%)$ & - & $1(2.5 \%)$ \\
\hline Peer evaluation builds trust among teachers. & $5(12.5 \%)$ & $12(30 \%)$ & $17(42.5 \%)$ & $3(7.5 \%)$ & $3(7.5 \%)$ \\
\hline $\begin{array}{l}\text { For peer evaluation to be successful, it must } \\
\text { be done once in a life time. }\end{array}$ & - & $5(12.5 \%)$ & $7(17.5 \%)$ & $10(25 \%)$ & $18(45 \%)$ \\
\hline
\end{tabular}


Thematic relations were sought in grouping the questionnaire items and the results were shown and discussed under the categories of the 'importance of peer review' (Figure 1), 'tutors' preference' (Figure 2), 'review focus' (Figure 3), 'fear for subjectivity' (Figure 4), and 'peer review and experience' (Figure 5) as follows:

\subsection{Importance of Peer Review}

The respondents' score on the significance of peer review of teaching which presents their perceptions about its importance is summarised in Figure 1 below.

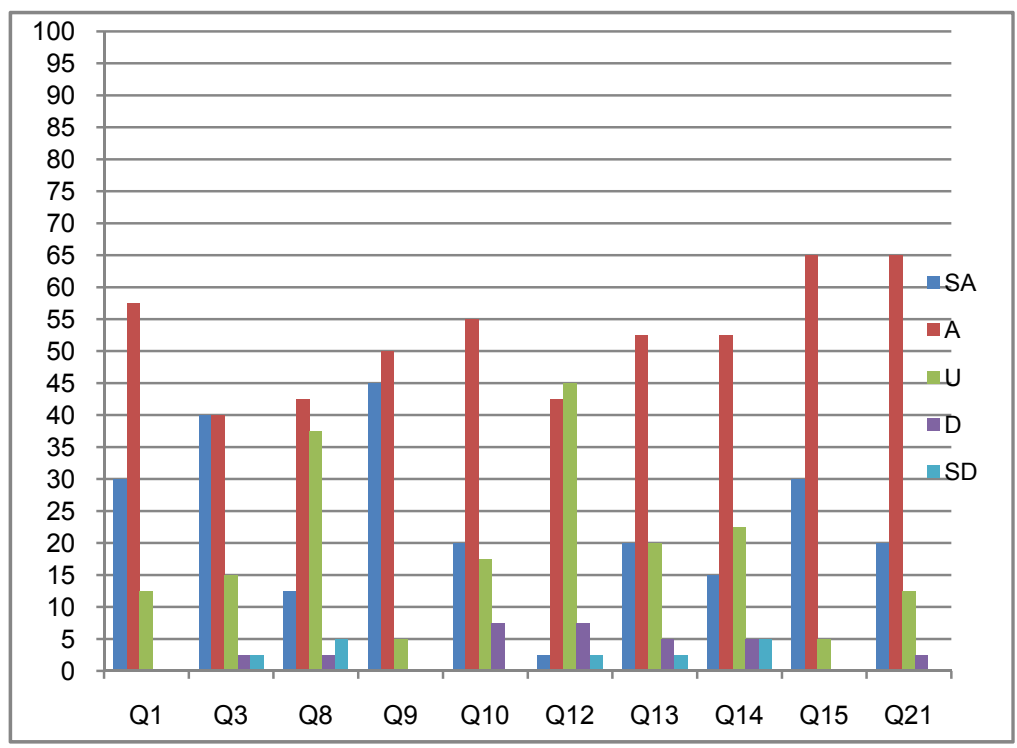

Figure 1. Importance of peer review

The study's first question explores the significance of peer review of teaching as perceived by teachers. Item (1) in the questionnaire was about whether the respondents considered peer review as useful in the teaching practice. The analysis revealed that (30\%) "strongly agreed", and $(57.5 \%)$ "agreed" that peer review was useful in teaching. This finding suggests that the informants believed that peer review has relevance to teaching and professional development. In addition, this result confirms the relevance of peer review of teaching practice for enhancing the quality of teaching as argued by Biggs and Tang (2007). On the other hand (12.5\%) were "uncertain" about their stand. Item (3) was designed to examine teachers' perceptions about the feedback provided by colleagues, where the respondents scored the same for "strongly agree" and "agree" $(40 \%)$ that they appreciated positively the feedback given by peers. There were $(15 \%)$ "uncertain", $(2.5 \%)$ who "disagreed" and (2.5\%) "strongly disagreed" that they looked positively about peer evaluation. It could be argued that the way peer review is executed in an institute plays a role in shaping teachers' perceptions either positively or negatively. This finding is significant as it accords with Bodenhausen's (1990) call for considering factors shaping teachers' reactions towards peer review of teaching. The analysis of item (8) revealed that $(12.5 \%)$ "strongly agreed", and (42.5) "agreed" that peer evaluation helped them in establishing positive relations with colleagues, whereas (37.5\%) were "uncertain" about their stand. On the other hand, $(5 \%)$ "disagreed", and $(2.5 \%)$ "strongly disagreed" that peer review assisted in keeping good relations with other colleagues. This result is important as it serves the study's first question, confirms the findings reported by Saarinen (2010); Danielson and MacGreal (2000), and suggests the fact that peer review was taken cautiously by some teachers who felt peer feedback might cause rift among colleagues. In addition, the social solidarity, for some teachers, is something that should not be sacrificed for the sake of any managerial procedure and as such peer feedback should always be positive. It could be argued that it is sometimes difficult to convince some teachers to act as critical friends and accept reviewers' feedback positively. Thus, lecturers' willingness to participate in peer evaluation may contribute to more constructive and less controversial feedback.

The respondents' perceptions about the significance of peer review in motivating them to reflect on their teaching were examined in item (9). Consistent with their responses to item (1) in the questionnaire, (45\%) "strongly agreed", and (50\%) "agreed' that peer review enabled them to reflect on their teaching, whereas (5\%) 
were "uncertain" about their stand. This result is significant as it accords with what Biggs and Tang (2007) observed about the positive effects of reflection in good teaching as they argued that "an important aspect to effective teaching is reflective practice, using transformative reflection, which enables teachers to create an improved teaching environment suited to their own context" (p. 31). Thus, viewing and designing peer review as a tool for transformative reflection is postulated to provide great opportunities for establishing the kind of climate that will optimise effective teaching and good practices. Item (10) was designed to examine the way teachers looked at the reviewers' feedback. The analysis revealed that (20\%) "strongly agreed", and (55\%) "agreed" that all feedback given was useful. On the other hand, (17.5\%) responded as "uncertain", and (7.5\%) "strongly disagreed" that all peer review feedback was useful. The percentage of those who perceived peer evaluation as partially useful, though less significant, suggests that not all teachers felt that the reviewers' feedback was always accurate. However, the overall result here is consistent with the informants' responses to items (1, 3, and 9). The analysis of item (12) revealed another interesting result pertaining to the teachers' feelings about peer feedback with (42.5\%) who "agreed", and (2.5\%) "strongly agreed" that peer review has been constructive all the time. Interestingly, $(45 \%)$ were "uncertain" about their view, while $(2.5 \%)$ "disagreed", and (7.5\%) "strongly disagreed" with the statement. The variation in the respondents' views here conflicts with their response to item (10) and might be attributed to the view held by some teachers that peer evaluation might be affected by some negative factors (item 8 ) in the questionnaire.

As far as the relation between peer evaluation and professional development is concerned, the analysis of item (13) revealed that $(52.5 \%)$ of the respondents "agreed', and (20\%) "strongly agreed" that peer review enhanced their professional growth. Those who chose "uncertain" scored (20\%) from the total responses, while (2.5\%) "disagreed", and (5\%) "strongly disagreed" that peer review helped them grow professionally. In fact, one of the prime objectives of quality assurance system is teachers' continuous learning through reflection for professional development, whose effective tool is peer review. Thus, teachers' understanding of the significance of peer review for professional development is better supported for active teacher involvement in the process of teaching quality, effective learning and teacher professional development. In the same vein, Lomas and Nicolls (2005) called for viewing peer review as an effective factor for enhancing teaching quality and teachers' professional development. In drawing on the significance of peer review for the scholarly activities, item (14) revealed that $(52.5 \%)$ of the informants "agreed", and (15\%) "strongly agreed" that peer evaluation motivated them to indulge in research activities. The respondents who were "uncertain" of the significance of peer review in developing sense and interest for research scored (22.5\%), and both those who "disagreed" and "strongly disagreed" with the idea in the item scored the same percentage (5\%). It is interesting to find that peer review stimulates teachers' interest for research as a part of professional development. Such an understanding among teachers is deemed useful for the learning process itself. In other words, peer review provides teachers with opportunities for formative feedback that motivates good teaching practices underpinned by scholarly activities. The analysis of item (15) revealed a significant result in support of the positive effects of peer review for teaching. (30\%) of the respondents "strongly agreed", and $(65 \%)$ "agreed" that peer evaluation helped them to modify their teaching methods. Only (5\%) of the respondents were "uncertain" about their stand. This result serves the study's second and third questions and confirms the report by Biggs and Tang (2007) on the significance of feedback on teaching and teacher personal and professional growth. It is worth noting here that the essence of peer review is to provide teachers with constructive feedback so that they reflect on their teaching experience and improve their practice. Peer review then keeps teachers in continuous reflection, modification, and adjustment which all lead to professional development and enhancement of good learning. The respondents' perceptions about the effects of peer review on personal growth and self-confidence development were explored in item (21). The analysis of this item revealed that (20\%) "strongly agreed", (65\%) "agreed" that peer review gave them more self-confidence. On the other hand, (12.5\%) appeared to be "uncertain" of their stand, while the score for "strongly disagree" was (2.5\%). It is observed that the percentages of those who supported the statement suggest the idea that the respondents held positive opinion by perceiving peer evaluation as useful for enhancing self-confidence. This result is consistent with the respondents' responses to items $(1,3,8,9,10,12,13,14$, and 15) in the questionnaire. 


\subsection{Tutors' Preference}

Figure 2 below presents a summary of the respondents' score on their preferences of peer review.

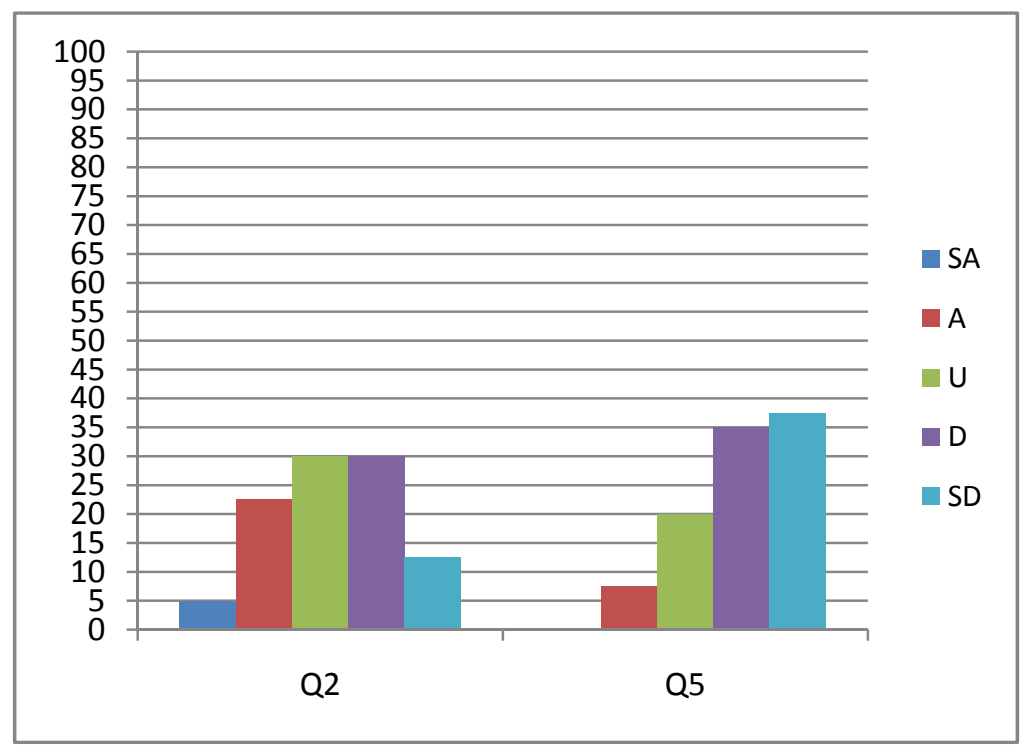

Figure 2. Tutor's preference

In an attempt to ascertain the tutors' choices and preferences for reviewers, item (2) explored whether tutors preferred to select their reviewers and reviewees or were open to receive and give feedback to a non-friend colleague. The analysis revealed that (5\%) of the respondents "strongly agreed", and (22.5\%) "agreed" that they felt comfortable with peer feedback if they selected their reviewers. On the other hand, the respondents scored $(30 \%)$ for both "uncertain" and "strongly disagree", while (12.5\%) "disagreed" that they preferred to choose their reviewers and those to evaluate as well. It could be argued that giving peer review participants the right to choose their review partners might motivate teachers' involvement in the process. It is worth noting that peer review of teaching is a flexible process that seeks teachers' willingness for participation. Item (5) examined the respondents' perceptions about peer review as a process for feedback exchange among friends. The analysis revealed that $(7.5 \%)$ of the respondents "agreed" that they could carry out peer review with friends only. On the other hand, (20\%) were "uncertain", while (37\%) "disagreed", and (35.5\%) "strongly disagreed" that they could exchange feedback with friends only. The findings here serve the study's first question which explores the teachers' perceptions of peer review of teaching. It is interesting to observe that the percentages of the responses to items (2) and (5) are consistent in reflecting the respondents' openness and willingness for participating in peer evaluation with non-friend colleagues. It could be argued that, in this context, tutors' preference is feedback for transformative reflection which encourages continuous learning and adjustment rather than social gains and group solidarity. The result supports the views of Danielson and MacGreal (2000) who suggested that if peer review is provided with a professional and supportive environment, teachers will be willing to view it positively without any suspicion or trepidation. 


\subsection{Review Focus}

Figure 3 below provides a summary of the respondents' score in relation to the review focus.

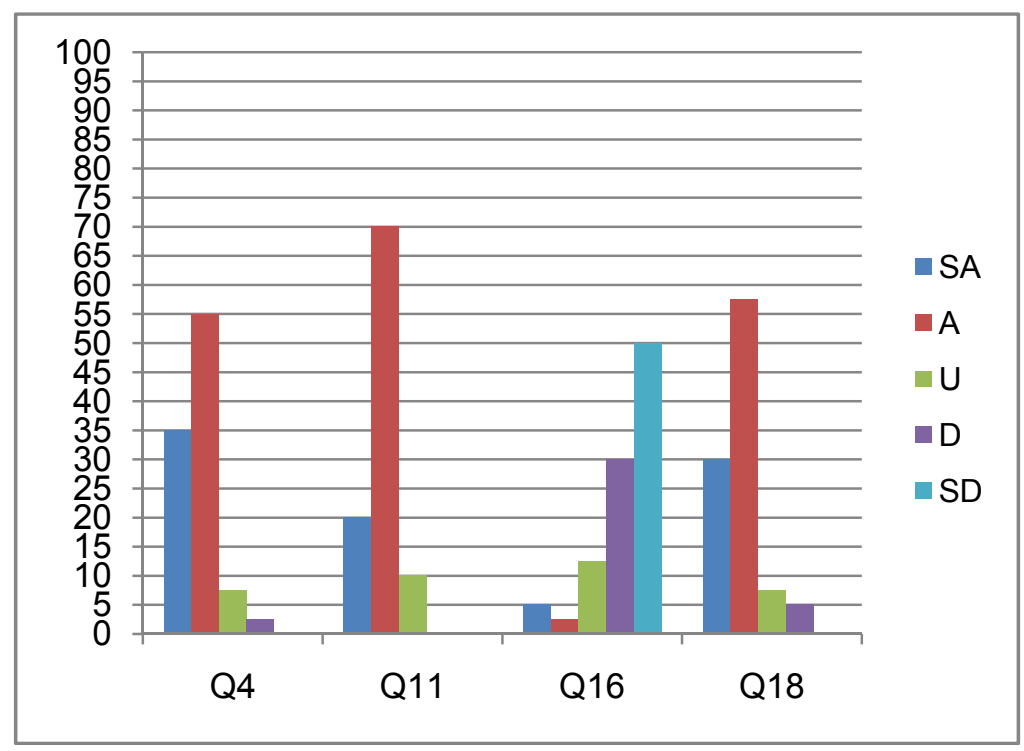

Figure 3. Review focus

Peer review is believed to draw individuals' attention to certain aspects for improvement and to support positive points and good practices as well. Hence, the respondents were asked about their focus, expectations and understanding of peer review and the feedback out of that. The analysis of item (4), Figure 3, revealed that (35\%) of the informants "strongly agreed", and (55\%) "agreed" that they found it interesting to share and exchange feedback with colleagues through peer review. On the other hand, $(7.5 \%)$ were "uncertain", while $(2.5 \%)$ "strongly disagreed" that they found it interesting to share feedback with colleagues. This finding serves the study's first question as it throws light on the significance of peer review in giving teachers opportunities to provide supportive feedback to colleagues and reflect on their own teaching and practices. In addition, this finding is consistent with the view expressed by Cowan (2006) that quality-oriented teaching factors such as peer review enable teachers to reflect on their practice, develop sense of professionalism and motivate learners for more effective learning. It could be argued that involvement in peer review enables teachers to evaluate and support each other, learn from others' perspectives, and improve one's own teaching and performance. However, for peer review to achieve such goals, peer evaluation must be done in a collegial and professional manner. Item (11) examined the respondents' focus and use of peer review. The analysis revealed that $(20 \%)$ of the respondents "strongly agreed", and (70\%) "agreed" that peer review offered a platform for giving colleagues some constructive feedback and practical suggestions. However, only $(10 \%)$ appeared "uncertain about their stand. This result serves the study's third question and suggests that teachers found peer review an effective factor in stimulating professional growth and improving effective teaching. Moreover, peer review in its social context provides opportunities for teachers to exchange formative feedback with colleagues, reflect on their practice, and it motivates effective teaching which affects positively the learning environment.

The analysis of item (16) which examined the respondents' understanding of the objectives of peer review and the decisions they made while evaluating colleagues revealed that (5\%) of the informants "strongly agreed", and $(2.5 \%)$ "agreed" that they looked only for highlighting their colleagues' weaknesses. On the other hand, (12.5\%) were "uncertain" of their stand. Interestingly, (50\%) "disagreed", and (30\%) "strongly disagreed" that their main objective and focus was to rate colleagues' weaknesses. This finding reveals the fact teachers tended to provide constructive and balanced feedback on both good practices and areas of improvement without resorting to selectivity by focusing on weaknesses only. In fact, selectivity in peer evaluation by ignoring good practices and highlighting weaknesses only can be one of the factors that lead to bias and subjectivity. Thus, objective peer evaluation needs to bring constructive perspective on teaching and teacher professional development. Researchers argued that for peer review to be successful, it is necessary to eliminate all negative factors and make sure that peer evaluation is not bias and that reviewers act as critical friends whose aim is constructive 
perspective (Biggs \& Tang, 2007; Bodenhausen, 1990). The analysis of item (18) revealed that (30\%) of the respondents "strongly agreed", and (57.5\%) "agreed" that peer review drew their attention to certain areas that needed further attention and improvement. On the other hand, (7.5\%) were "uncertain", while (5\%) "strongly disagreed" that feedback given by peers helped them improve certain neglected areas whether personal or professional. This result serves the study's third question and is consistent with the respondents' response to item (13) and with the understanding that one of the main purposes of peer review is to provide teachers with opportunities for reflection and improvement in their teaching practices, personal growth and professional development. This view is strongly asserted by Danielson and McGreal (2000) who argued that peer evaluation has powerful effects on teaching as it directs teachers to concentrate their reflection on the areas they need to improve.

\subsection{Fear for Subjectivity}

The respondents' score on the questionnaire items regarding the concerns about peer review of teaching is given in Figure 4 below.

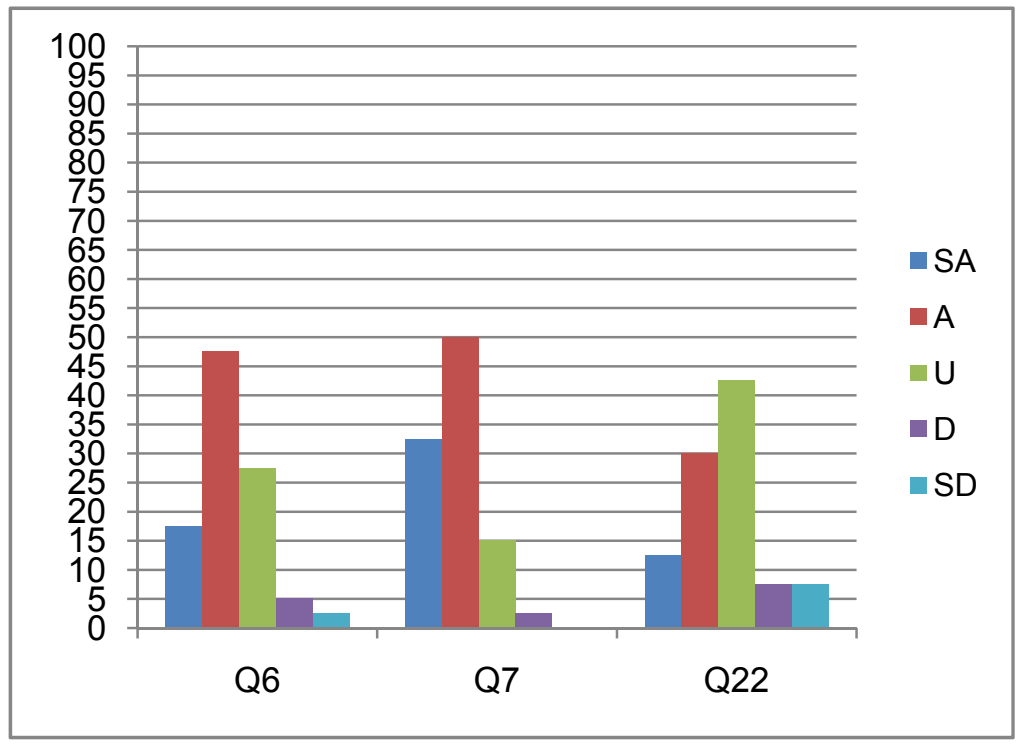

Figure 4. Fear for subjectivity

It has been observed that peer review was taken by some cautiously and with fear of creating rooms for bias and subjectivity. One of the main objectives of this study as reflected in its fourth question is to examine teachers' fear and to try to understand the degree to which such fear affects teachers' beliefs in peer evaluation as a quality assurance instrument. The analysis of item (6) revealed that (17.5\%) of the respondents "strongly agreed", and (47.5\%) "agreed" that peer review might be bias sometimes. On the other hand, $(27.5 \%)$ were "uncertain", while $(2.5 \%)$ "disagreed", and (5\%) "strongly disagreed" that peer review might be bias sometimes. In the same vein, the analysis of item (7) revealed that (32.5\%) "strongly agreed", and (50\%) "agreed" that misunderstanding among teachers creates a high possibility for subjectivity and as such jeopardising any opportunity for a fair and an objective peer evaluation. Six of the respondents' remained "uncertain" of their stand with $(15 \%)$, while (2.5\%) "strongly disagreed" with the idea that peer review doesn't work objectively when there is some misunderstanding among teachers. This result is significant as it serves the study's fourth question and throws some light on the causes of the controversies and debates in peer evaluation. The result is also consistent with the research which reported that teachers sometimes approached peer review with some concerns and trepidation (Saarinen, 2010; Bodenhausen, 1990). If practiced in a safe and professional context, peer review may maximise possibilities for effective teaching, professional development and effective learning. It could be argued further that the elimination of factors that lead to the creation of negative energy will assure fair and reliable peer review as well as teachers' willingness to participate in the process. Moreover, the analysis of item (22) revealed that $(12.5 \%)$ of the respondents "strongly agreed", and $(30 \%)$ "agreed" that peer review helped in building trust among teachers. However, (42\%) were "uncertain", while the score for both "disagreed", and "strongly disagreed" that peer review facilitated building trust among teachers and helped teachers to view peer evaluation 
as a source of constructive perspective from critical friends rather than as 'criticisms' at someone's performance was $(7.5 \%)$ each. The results of this section serve the study's fourth question and support the need for encouraging active participation of teachers in the peer review process (Biggs \& Tang, 2007). For peer review to be reliable and less-threatening, teachers' willingness to participate in the process is of significant importance.

\subsection{Peer Review and Experience}

Figure 5 summarizes the score of the respondents' views about the relation between peer evaluation and experience.

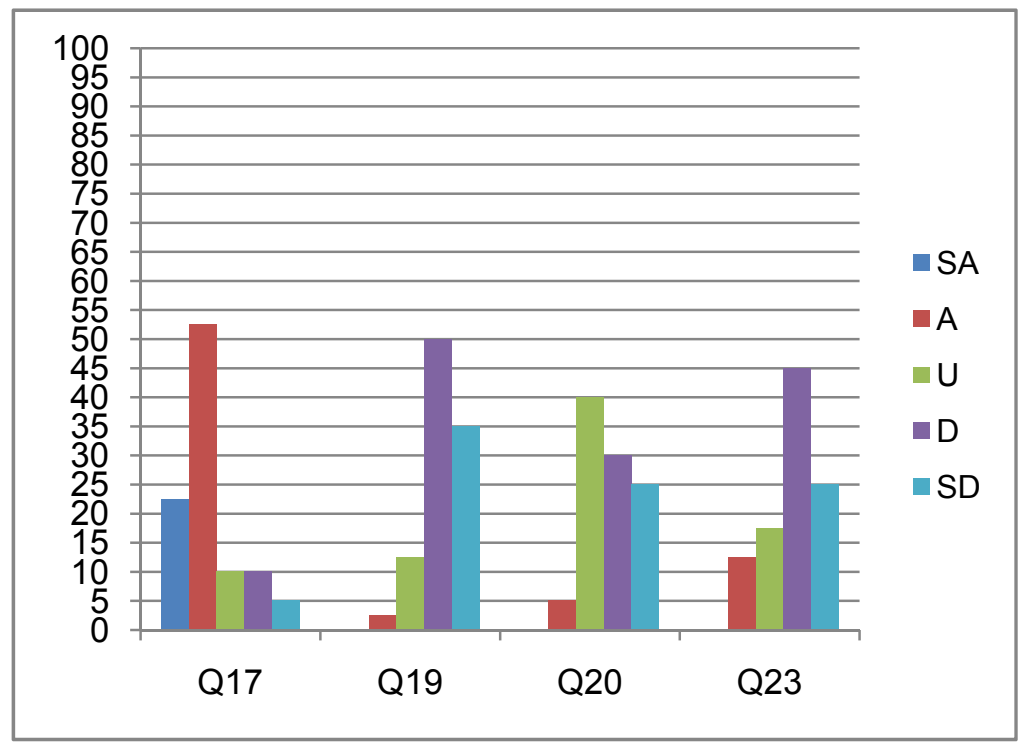

Figure 5. Peer review and experience

The analysis of item (17), Figure 5, revealed that (22.5\%) of the respondents "strongly agreed", and (52.5\%) "agreed" that they preferred to negotiate additional oral feedback with reviewers during review sessions. On the other hand, the respondents scored (10\%) for both "uncertain" and "strongly disagree", and (5\%) for "disagree" to the idea of receiving further additional oral feedback from reviewers, preferring to have formative feedback on paper. Teachers' support for a follow-up meeting indicates the interest teachers have for peer feedback and this creates another opportunity for reflection and mutual learning. Peer written and verbal feedback, according to Sullivan et al. (2012), is perceived by teachers as an effective factor for reflection for it addresses the teachers' need for improvement and professional growth. The analysis of item (19) revealed that (2.5\%) of the respondents "agreed" that with rich experience, in teaching, peer review was not necessary and as such it did not add to them anything. (12.5\%) were "uncertain", while (35\%) "disagreed", and (50\%) "strongly disagreed" that with experience in teaching peer review was not necessary. This result serves the study's first question and suggests that the majority of the respondent teachers understood the relevance of peer review of teaching as one of the crucial parts of quality teaching and learning, and the necessity of feedback for reflection and continuous professional development. This observation accords with the view that quality-driven teaching motivates effective and purposeful learning (Cowan, 2006). Item (20) focused on the involvement of teachers of different experience levels in providing feedback on teaching and the perceptions of senior teachers toward such feedback. The analysis revealed that $(5 \%)$ of the informants "agreed" that junior colleagues were unable to provide effective feedback. On the other hand, (40\%) were "uncertain" of their stand, while (25\%) "disagreed", and (30\%) "strongly disagreed" with the statement in the item by giving more value to feedback provided by the less-experienced colleagues. This result is significant in a sense that it serves the study's first question and reveals at the same time the fact that the bulk majority of the respondents were in favour of feedback given through peer review regardless of reviewers' experience in teaching. It could be argued further that peer review minimises the gap between teachers as it enhances junior teachers' sense of professionalism and gives experienced teachers a chance to appreciate other teachers' feedback. The study also explored the respondents' view on conducting peer review on regular basis. The analysis of item (23) revealed that $(12.5 \%)$ of the respondents "agreed" to have peer evaluation once in their career, while (17.5\%) were "uncertain" about their 
stand. On the other hand, (25\%) "disagreed", and (45\%) "strongly disagreed" to experience peer review once in a lifetime. This suggests the tendency of teachers to keep peer review as a tool that enhances quality teaching and professional development. Thus, when teaching is informed and supported by constructive feedback, teachers are expected to have high expectations for professional growth and motivating students' effective learning. This is true because "expert teachers continually reflect on how they might teach even better" (Biggs \& Tang, 2007, p. 41).

\section{Conclusion}

This study attempted to examine the perceptions of teachers about peer evaluation or review of teaching as a factor for quality enhancement and professional development. The analysis of data provided varieties of insights into the teachers' perceptions of peer review as a process in the quality assurance system. Overall, the results of this study were supportive of the relevance and effectiveness of peer review for the teaching profession as perceived by the respondents. The evidence of the teachers' positive perceptions together with some fear of bias towards peer review exercise provides important professional implications for teaching profession within quality enhancement context. The study's focus on both positive perceptions and 'reservations' over peer review by teachers provided some insights on the importance of peer review in enhancing quality teaching and professional growth. For peer review to be more effective, a special care needs to be given to its social dimension to assure that reviewers act as critical friends providing constructive feedback in a professional and collegial manner without any subjectivity or bias. Furthermore, there must be some consistency in the interpretation, outlining policies and implementation of peer review or evaluation practice by institutes of higher education which adopt it.

To conclude, peer evaluation or review of teaching is a necessary process in today's teaching practices and as such it should be encouraged and promoted among teachers. In this regard, institutes of higher learning may need to encourage research activities among academic staff, encourage good teaching practices and innovative ideas, outline teaching standards, and promote quality assurance culture and professionalism as well as cooperative competition. In addition, the establishment of teaching development centres for enhancing academic performance and training is deemed necessary in promoting quality teaching for quality learning practices and by so doing controversies over peer review may change to willingness to participate in the process.

\section{References}

Biggs, J., \& Tang, C. (2007). Teaching for quality learning at university (3rd ed.). New York: Society for Research into Higher Education \& Open University Press.

Bodenhausen, J. (1990). Teacher attitudes toward peer evaluation: What shapes them? Paper presented at the Annual Meeting of the American Educational Research Association, Boston, April 16-20, 1990. Retrieved from http://www.eric.ed.gov/PDFS/ED

Borich, G. (2004). Effective teaching methods (5th ed.). New Jersey: Pearson.

Celce-Murcia, M. (Ed.). (2001). Teaching English as a second or foreign language (3rd ed.). USA: Heinle \& Heinle.

Cowan, J. (2006). On becoming an innovative university teacher: Reflection in action (2nd ed.). New York: Society for Research into Higher Education \& Open University Press.

Danielson, C., \& McGreal, T. (2000). Teacher evaluation. USA: Educational Testing Service.

Karavas-Doukas, E. (1996). Using Attitude scales to investigate teachers' attitudes to the communicative approach. English Language Journal, 50(3), 187-198. http://dx.doi.org/10.1093/elt/50.3.187

Kumrow, D., \& Dahlen, B. (2002). Is peer review an effective approach for evaluating teacher? The Clearing House, 75(5), 238-241. http://dx.doi.org/ 10.1080/00098650209603947

Laresen-Freeman, D., \& Long, M. (1991). An introduction to second language acquisition research. London: Longman.

Lomas, L., \& Nicholls, G. (2005). Enhancing teaching quality through peer review of teaching. Quality in Higher Education, 11(2), 137-149. http://dx.doi.org/10.1080/13538320500175118

Richards, J., \& Schmidt, R. (2002). Longman dictionary of language teaching \& applied linguistics (3rd ed.). London: Pearson Education.

Saarinen, T. (2010). What I talk when I talk about quality. Quality in Higher Education, 16(1), 55-57. http://dx.doi.org/10.1080/13538321003679507 
Sullivan, P., Buckle, A., Nicky, G., \& Atkinson, S. (2012). Peer observation of teaching as a faculty development tool. BMC Medical Education, 12. http://dx.doi.org/10.1186/1472-6920-12-26

\section{Appendix}

\section{Questionnaire}

\section{Dear colleagues:}

This questionnaire forms part of a study about exploring the effects of peer review on quality of teaching I am currently undertaking. The researcher would therefore very much appreciate if you could spend a little time to respond honestly and objectively to this questionnaire. Your responses will help me to identify preferences, and perceptions within quality teaching and learning context. Kindly be informed that the questionnaire is conducted for research purposes only.

This questionnaire consists of two parts. Part I focuses on your teaching experience. Part II deals with the effects of peer review practice as perceived by you. Please respond to All the items in this questionnaire precisely.

I thank you in advance for your cooperation and help with this research.

General instruction: Please respond to all the items/questions in the questionnaire.

\section{Part I}

Please provide relevant information by filling in the blank spaces below:

1. Years of experience in teaching:

\section{Part II}

Please respond to the following statements by placing a tick $(\sqrt{ })$ mark in the box that represents your attitude.
5= Strongly Agree
4= Agree
3=Uncertain
2= Disagree
1= Strongly Disagree

\begin{tabular}{|c|c|c|c|c|c|c|}
\hline & Statements & S.A & A & $\mathrm{U}$ & $\mathrm{D}$ & S.D \\
\hline 1 & Peer evaluation is useful in teaching. & & & & & \\
\hline 2 & $\begin{array}{l}\text { I prefer to choose my reviewer(s) and } \\
\text { reviewee(s). }\end{array}$ & & & & & \\
\hline 3 & $\begin{array}{l}\text { I always look positively about peer } \\
\text { evaluation. }\end{array}$ & & & & & \\
\hline 4 & $\begin{array}{l}\text { In the peer evaluation sessions, I found } \\
\text { it interesting to exchange feedback with } \\
\text { colleagues. }\end{array}$ & & & & & \\
\hline 5 & $\begin{array}{l}\text { I can only carry out peer evaluation } \\
\text { with friends. }\end{array}$ & & & & & \\
\hline 6 & Peer evaluation may be bias sometimes. & & & & & \\
\hline 7 & $\begin{array}{l}\text { Peer evaluation doesn't work } \\
\text { objectively when there is some } \\
\text { misunderstanding among staff. }\end{array}$ & & & & & \\
\hline 8 & $\begin{array}{l}\text { Peer evaluation helps me to develop } \\
\text { positive relations with my colleagues. }\end{array}$ & & & & & \\
\hline 9 & $\begin{array}{l}\text { Peer evaluation enables me to reflect on } \\
\text { my teaching positively. }\end{array}$ & & & & & \\
\hline 10 & I find all reviewers' feedback useful. & & & & & \\
\hline
\end{tabular}




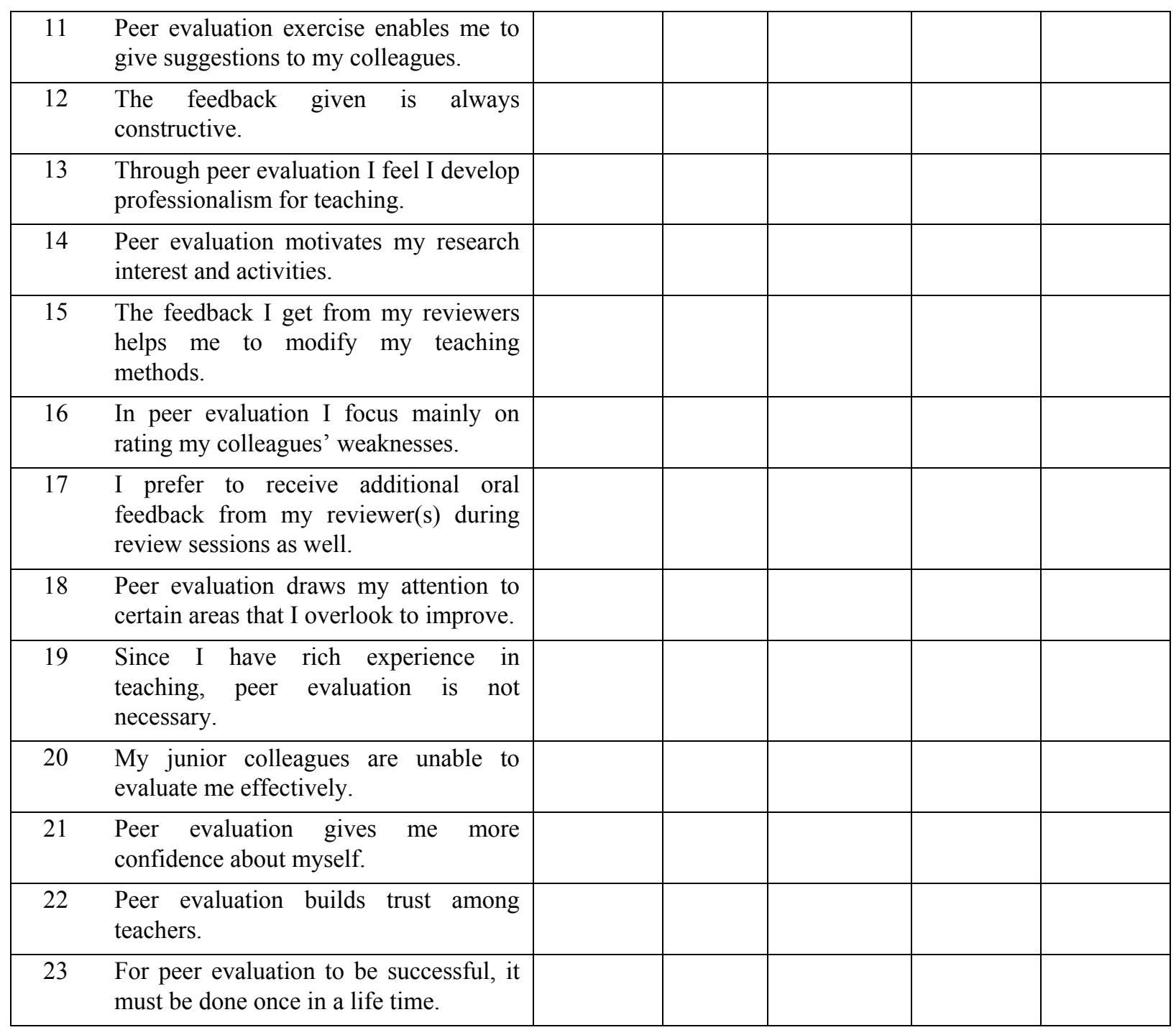

